\title{
Absence of Evidence or Evidence of Absence - A Review of the Evidence for Hydroxychloroquine as a Potential Candidate for Prophylaxis against COVID-19
}

Cara Usher ${ }^{1,2,3,}{ }^{*}$, Lea Trela-Larsen 1,2,3, Emer Fogarty 1,2,3, Aisling O'Leary ${ }^{1,2,3}$, Stephen Capper ${ }^{1,2,3}$, Ellen P. O'Sullivan $^{2,3}$, Caitriona NiChoitir ${ }^{1,2,3}$, Cathal Walsh ${ }^{3,4}$, Michael Barry ${ }^{1,2,3}$ and Roisin Adams ${ }^{1,2,3}$

${ }^{1}$ National Centre for Pharmacoeconomics, Dublin, Ireland

${ }^{2}$ Trinity College Dublin, Ireland

${ }^{3}$ St. James's Hospital, Dublin 8, Ireland

${ }^{4}$ University of Limerick, Ireland

\begin{abstract}
Clinical trials are investigating several agents as potential options for pre-exposure prophylaxis and post-exposure prophylaxis to prevent infection with COVID-19. A particular focus has been high risk groups including healthcare workers. Chloroquine (CQ) and hydroxychloroquine (HCQ) are the predominant agents in terms of numbers of clinical trials listed on Clinicaltrials.gov. However, CO/HCQ have not been proven as an effective treatment option for COVID-19, and it is currently unclear what benefit, if any, is available to support their use in a prophylactic role. Four randomised control trials have been published so far which have examined the effect of $\mathrm{HCQ}$ as pre-exposure (PrEP) and post-exposure prophylaxis (PEP). This study summarises the evidence to date for HCQ as a potential prophylactic option for PEP and PrEP, presents both the aggregated and disaggregated data and details the gaps in the evidence base. The absolute risk differences for the pre-exposure prophylaxis studies were $-0.3 \%$ to $-2 \%$ and for the post prophylaxis studies were $-0.6 \%$ and $-2.4 \%$. There were more adverse events noted in the hydroxychloroquine arms across all four studies.
\end{abstract}

Keywords

Hydroxychloroquine, Pre-exposure prophylaxis, Post-exposure prophylaxis, COVID-19

\section{Introduction}

In May 2020, Amnesty International reported that more than 3,000 health care workers had died from COVID-19 across 79 countries [1]. This number probably represents a fraction of the true global death toll of health care workers because of factors including poor documentation of deaths in some countries, inconsistently defining health care workers across countries as well as data obfuscation [1]. Health care workers are the most valuable resource for every country to combat the disease, yet one of the greatest risks to the health-care system is a high rate of SARS-CoV-2 infection among them and the consequent lack of skilled staff to ensure a functioning local or regional response to the pandemic [2]. The healthcare giving setting is at heightened risk due to a number of factors including difficulties implementing usual public health strategies such as social distancing as well as proximity to infected patients and potential involvement in aerosol generating procedures. Steps to reduce transmission within the healthcare delivery environment could minimize the overall impact on the healthcare system. Strategies such as pre-exposure (PrEP) and post-exposure prophylaxis (PEP) with antimicrobial drugs have been demonstrated to be effective in other diseases. For example, PEP with rifampicin is given to people exposed to index cases of invasive meningococcal infection, and oseltamivir has been recommended by WHO for people at high risk of infection before or after exposure to pandemic influenza [3]. PeP is administered following needle stick exposure to HIV. PEP was first attempted for HIV prevention in the 1980 s among health care workers who

*Corresponding author: Dr. Cara Usher, National Centre for Pharmacoeconomics, Dublin, Ireland; Trinity College Dublin, Ireland; St. James's Hospital, Dublin 8, Ireland

Accepted: February 02, 2021

Published online: February 04, 2021

Citation: Usher C, Larsen LT, Fogarty E, et al. (2021) Absence of Evidence or Evidence of Absence - A Review of the Evidence for Hydroxychloroquine as a Potential Candidate for Prophylaxis against COVID-19. Ann Public Health Reports 5(1):160-165 
Citation: Usher C, Larsen LT, Fogarty E, et al. (2021) Absence of Evidence or Evidence of Absence - A Review of the Evidence for Hydroxychloroquine as a Potential Candidate for Prophylaxis against COVID-19. Ann Public Health Reports 5(1):160-165

experienced occupational exposures. At that time, only AZT (zidovudine) was available. Anecdotal evidence of success began to accumulate, leading to the first formal study of PEP effectiveness, a case-control study of occupational exposures. This study demonstrated an $81 \%$ reduction in HIV infection in those who received AZT alone compared with those who did not receive any treatment [4]. In more recent years, PrEP has also demonstrated to be a highly effective strategy for preventing HIV in high risk cohorts [5-7]. In 2015, based on the results of trials, the World Health Organization (WHO) recommended that PrEP should be offered as an additional prevention option for people at substantial risk of HIV infection [8]. Taking a prophylactic medication to prevent an infection in the absence of a vaccine has proven to be an effective approach in other conditions such as malaria.

Early in the COVID-19 pandemic hydroxychloroquine and chloroquine were suggested to be of benefit in treating and preventing COVID-19 due to an ability to inhibit receptor binding and membrane fusion, two critical steps required for cell entry by coronavirus [9]. Hydroxychloroquine is preferred due to a better clinical safety profile, possible higher daily dose, and fewer pharmacologic interactions [10-12]. However randomised controlled studies published to date have demonstrated a lack of benefit of hydroxychloroquine in effectively treating COVID-19 $[13,14]$.

A search of clinicaltrials.gov revealed 68 studies exploring the benefit of hydroxychloroquine as a prophylactic agent either in the PrEP or the PeP phase [15]. A number of randomised controlled studies have already reported with varying results [16-19]. This review summarises the randomised controlled studies that have been published and compares them under population, intervention, comparator, outcomes, timing, study design (PICOTS). We have provided a common estimate of treatment effect and in doing so we highlight the challenges of pooling such studies and drawing conclusions from same, and address the question of what is required of trials in order to demonstrate a robust effect.

\section{Summary of RCTs Published}

In total four unique RCTs have published so far and have included in total $n=6,438$ participants. Two of these studies examined a PEP type regimen (Boulware and Mitja) and two examined a PrEP regimen (Rajasingham and Abella). A summary of the trials is provided in Table 1 described by their PICOTS.

Table 1: Summary of clinical trials of hydroxychloroquine prophylaxis for COVID-19.

\begin{tabular}{|c|c|c|c|c|c|c|}
\hline $\begin{array}{l}\text { Trial (Author, } \\
\text { Year, study } \\
\text { country) }\end{array}$ & Population & Intervention & Comparator & Outcome & $\begin{array}{l}\text { Timing } \\
\text { Maximum time } \\
\text { from exposure } \\
\text { to intervention }\end{array}$ & Study Design \\
\hline $\begin{array}{l}\text { Boulware } 2020 \\
\text { (n=821) } \\
\text { United States } \\
\text { and Canada }\end{array}$ & $\begin{array}{l}\text { Adults }>18 \text { yrs } \\
\text { post household or } \\
\text { occupational exposure to } \\
\text { confirmed COVID-19 } \\
\text { Post Exposure prophylaxis }\end{array}$ & $\begin{array}{l}\text { Hydroxychloroquine } \\
800 \text { mg once, } \\
\text { followed by } 600 \mathrm{mg} \\
\text { in } 6-8 \mathrm{hrs} \text { followed } \\
\text { by } 600 \mathrm{mg} \text { once daily } \\
\text { for } 4 \text { additional days }\end{array}$ & Placebo & $\begin{array}{l}\text { Primary: PCR } \\
\text { confirmed or } \\
\text { probable COVID-19 } \\
\text { (self reported) }\end{array}$ & Up to 6 days & $\begin{array}{l}\text { Randomised } \\
\text { double blind } \\
\text { placebo } \\
\text { controlled }\end{array}$ \\
\hline $\begin{array}{l}\text { Mitja } 2020 \\
(n=2,134) \\
\text { Spain }\end{array}$ & $\begin{array}{l}\text { Adults }>18 \text { yrs healthcare } \\
\text { worker }{ }^{*} \text {,nursing home } \\
\text { residents, household post } \\
\text { exposure to confirmed } \\
\text { COVID-19 } \\
\text { Post-exposure Prophylaxis }\end{array}$ & $\begin{array}{l}\text { Hydroxychloroquine } \\
800 \text { mg once, and } \\
\text { then } 400 \text { mg daily } \\
\text { for } 6 \text { days }\end{array}$ & $\begin{array}{l}\text { No specific } \\
\text { therapy }\end{array}$ & $\begin{array}{l}\text { Primary: PCR- } \\
\text { confirmed } \\
\text { symptomatic } \\
\text { Covid-19 within } 14 \\
\text { days }\end{array}$ & Up to 7 days & $\begin{array}{l}\text { Open label } \\
\text { cluster- } \\
\text { randomised }\end{array}$ \\
\hline $\begin{array}{l}\text { Rajasingham } \\
2020 \\
\text { ( } n=1,483 \text { ) } \\
\text { United States } \\
\text { and Canada }\end{array}$ & $\begin{array}{l}\text { Adults }>18 \text { yrs healthcare } \\
\text { worker with ongoing } \\
\text { exposure to persons with } \\
\text { SARS-CoV-2 } \\
\text { Pre-Exposure Prophylaxis }\end{array}$ & $\begin{array}{l}\text { Hydroxychloroquine } \\
400 \text { mg loading } \\
\text { dose followed by } \\
400 \text { mg in } 6-8 \text { hrs } \\
\text { followed by } 400 \\
\text { mg once or twice } \\
\text { weekly for } 12 \text { weeks }\end{array}$ & Placebo & $\begin{array}{l}\text { Primary: PCR } \\
\text { confirmed or } \\
\text { probable Covid-19 } \\
\text { (self reported) }\end{array}$ & & $\begin{array}{l}\text { Randomised } \\
\text { double-blind, } \\
\text { placebo- } \\
\text { controlled }\end{array}$ \\
\hline $\begin{array}{l}\text { Abella } 2020 \\
(n=125) \text { United } \\
\text { States }\end{array}$ & $\begin{array}{l}\text { Adults }>18 \text { yrs healthcare } \\
\text { workers with ongoing } \\
\text { exposure to persons with } \\
\text { COVID-19 } \\
\text { Pre-exposure Prophylaxis }\end{array}$ & $\begin{array}{l}\text { Hydroxychloroquine } \\
600 \text { mg daily for } 8 \\
\text { weeks }\end{array}$ & Placebo & $\begin{array}{l}\text { Primary: Incidence } \\
\text { of SARS-CoV-2 } \\
\text { infection as } \\
\text { determined by a } \\
\text { nasopharyngeal } \\
\text { swab during the } 8 \\
\text { weeks of treatment } \\
\text { (PCR confirmed } \\
\text { COVID-19) }\end{array}$ & & $\begin{array}{l}\text { Randomised } \\
\text { double blind } \\
\text { placebo } \\
\text { controlled }\end{array}$ \\
\hline
\end{tabular}

*Healthcare workers includes those working in nursing home

HCQ: Hydroxychloroquine; PrEP: Pre-exposure prophylaxis; PEP: Post-exposure Prophylaxis; PCR: Polymerase Chain Reaction. 
Citation: Usher C, Larsen LT, Fogarty E, et al. (2021) Absence of Evidence or Evidence of Absence - A Review of the Evidence for Hydroxychloroquine as a Potential Candidate for Prophylaxis against COVID-19. Ann Public Health Reports 5(1):160-165

\section{Population}

The population of interest in all studies was adults with exposure to SARS-CoV-2. Two of the studies included persons who were in the pre-exposure group $[18,19]$ and two were in the post-exposure groups $[16,17]$. In the post-exposure studies the majority of the participants were healthcare workers; both also included household exposure and one (Mitja) also included nursing home residents (12\%). The post-exposure cohort in Boulware did not show consistent proof of exposure to SARS-CoV-2 due to the lack of availability of testing for exposed persons; approximately $2 \%$ of cases were laboratory confirmed cases. The majority of cases in Mitja were laboratory confirmed (98\%). There were differences in the demographics of the populations included in these two post-exposure studies. The age distribution of the Boulware study participants was marginally younger (median age 40 yrs vs. 48 years in Mitja study). There were more women in the Mitja study than the Boulware ( $72 \%$ vs. $50 \%)$. The Boulware study participants appeared to be healthier than those in the Mitja study which included more patients with comorbidities. This may have been due to the strict exclusion criteria implemented for the Boulware study which excluded all participants with ischaemic heart disease, history of QT-interval irregularities and participants who were on medicines which could prolong QT interval. In both studies the majority of patients were enrolled within 6 days of exposure. The cut-off for enrolment in the Boulware trial was shorter at 6 days whereas the Mitja study allowed enrollment up to 7 days. The exposure risk was defined as high risk in the Boulware study if a participant was not wearing any PPE at the time of exposure and the majority of trial participants were in this group (88\%) whereas the majority of the trial participants in the Mitja study reported routine wearing of a mask (66\%).

In the pre-exposure study by Abella, et al. all participants ( $n=132$ ) were healthcare workers who were at risk of exposure to patients with COVID-19. The majority of participants were women with a median age 33 years. All participants wore full PPE. Participants with substantial cardiac disease were excluded. The pre-exposure study by Rajasingham (n $=1,483$ ) included hospital workers and first responders with ongoing exposure to COVID-19. The median age was approximately 41 years and while the majority were women the proportion of women was lower than in the Abella study (51\% vs. $69 \%$ respectively).

\section{Intervention}

The intervention in all studies was hydroxychloroquine in varying doses and durations. For the post-exposure studies the duration was shorter than in pre-exposure studies. In Boulware prophylaxis was administered over 5 days with a loading dose of $800 \mathrm{mg}, 600 \mathrm{mg}$ 6-8 hrs later followed by doses of $600 \mathrm{mg}$ given daily thereafter. In Mitja the total duration was 7 days with a loading dose of $800 \mathrm{mg}$ on day one followed by $400 \mathrm{mg}$ each day thereafter. In the pre-exposure studies hydroxychloroquine was administered for a total of 8 weeks in Abella, et al. at a dose of $600 \mathrm{mg}$ per day. In Rasjasingham, et al. prophylaxis was administered over 12 weeks in two different dosing schedules; cohort 1 received 400 mg week- ly and cohort 2 received $400 \mathrm{mg}$ twice weekly; both cohorts also received a loading dose of $2 \times 400 \mathrm{mg} \mathrm{6-8}$ hours apart. Adherence to the interventions was not monitored, and participants reported variable levels of adherence.

\section{Comparator}

Both post-exposure studies included a control arm however only Boulware included a placebo tablet. In the Mitja control arm participants received no therapy. In Boulware folate tablets were used as placebo and on day 14 masking was tested by asking participants which treatment they believed they were taking. In the hydroxychloroquine group $46.5 \%$ guessed correctly vs. $35.7 \%$ in the control group. Rajasingham also used a folate placebo tablet. Both pre-exposure studies included placebo as the comparator.

\section{Primary outcomes}

The primary outcome of importance is the number of infections or the rate of infection. While this was a common outcome measured across all four studies it was measured slightly differently. In the post-exposure study by Boulware infection was recorded if either a laboratory confirmed case was reported or a probable COVID-19 specific symptomatic case was reported. In Mitja COVID-19 positivity was confirmed by laboratory testing at day 1 and 14 . The primary outcome in the study by Rajasingham was Covid-19-free survival time by laboratory-confirmed or probable compatible illness. Over the course of the Rajasingham study period access to laboratory testing was poor therefore a composite primary outcome of probable COVID-19 based on compatible symptoms was included. For both studies (Boulware and Rajasingham) definitions of probable (symptoms based cases) were the same. The primary outcome in Abella was the rate of conversion to SARS-CoV-2 status following a PCR test at 4 weeks and 8 weeks provided they had a negative test at baseline.

Safety was included as secondary outcomes in all four studies. This was recorded in a similar way across the trials where a report of any adverse event was documented. Adverse events were reported to a greater extent in the hydroxychloroquine arms than the control arms however the numbers differed across the studies. This variation is likely due to the differing demographics across the studies as well as differing exclusion criteria, and not the adverse events themselves.

\section{Timing}

Timing is considered in two ways. Firstly we examine the post-exposure studies in terms of the timing of prophylaxis administration relative to the exposure. Secondly we review the timing of the studies in the context of the pandemic given the rise and fall of cases over the periods of these trials. Firstly in the post-exposure studies, the median time from exposure to enrolment in the Mitja study was 4 days (IQR 3-6) and in Boulware was 3 days. For $>50 \%$ of the study participants, the time from exposure to the index case to randomization was $\geq 4$ days.

All studies were undertaken in the initial wave of the global pandemic. A number of the studies were challenged by the 
Citation: Usher C, Larsen LT, Fogarty E, et al. (2021) Absence of Evidence or Evidence of Absence - A Review of the Evidence for Hydroxychloroquine as a Potential Candidate for Prophylaxis against COVID-19. Ann Public Health Reports 5(1):160-165

shortages or access to PCR testing. The Boulware study began recruitment in the peak of the pandemic and was primarily US based but also included parts of Canada. Around this time the US was undergoing significant testing capacity issues and as a result only a small number of the trial participants were laboratory confirmed. One study (Rajasingham) underwent problems with recruitment and had to terminate early. This was considered to have been influenced by the publication of the studies highlighting an increase in adverse events due to the hydroxychloroquine. The Abella study was the most recent study to recruit and complete (July to August 2020). This study also had to terminate early. It is possible that the changing disease frequency across the pandemic time span of when these studies were undertaken had an influence on the overall study results.

\section{Study design}

Three of the studies were randomised double blind placebo controlled studies; one was an open label cluster randomised study where the control arm was no specific therapy. The open label nature of the Mitja study may have introduced particular biases such as a selection bias, detection bias and reporting bias as well as performance bias. All participants in the Mitja study were followed-up in person at home or in the workplace whereas in the Boulware study the majority of baseline and follow-up data was conducted by self-report surveys via an online system. Detection and reporting bias was particularly evident between the PEP studies by Mitja and Boulware. In the open label Mitja study $51.6 \%$ of the hydroxychloroquine group reported an adverse event versus only $5.9 \%$ in the control group. In theory participants in Boulware were healthier given that the exclusion criteria were more strict than that of the Mitja study and there were more patients with co-morbidities that could have led to increased risk of adverse events. While the Mitja study did not explicitly exclude patients with cardiac co-morbidities it is possible that through the open label design patients may have been excluded who were more susceptible to adverse events or poor outcome. The Mitja study included some crossover from control to intervention following a positive PCR indicating infection. The Mitja study initially based the power calculation of the study on the relative effect size of $10 \%$ with $90 \%$ power to detect a difference of $10 \%$ assuming a $15 \%$ event rate in the control arm; however this was revised at the interim analysis to $80 \%$ power to detect a difference with $6.5 \%$ and $3 \%$ symptomatic infections in the control and intervention arms. The Boulware study assumed that there would be a $50 \%$ relative effect with a $90 \%$ power to detect a difference (alpha 0.05 ). It is not clear in the Mitja study how the alpha was adjusted to reflect the change to the power calculation at the interim stage.

The pre-exposure studies by Rajasingham and Abella were both double blind randomised control studies. Abella included a crossover upon positive PCR to hydroxychloroquine from placebo however no further information is available on whether participants did cross over. The Abella study was planned for $80 \%$ power at an alpha of $5 \%$ over the trial assuming an event rate of $10 \%$ in the control arm and $1 \%$ for hydroxychloroquine. Two interim analyses were planned which allowed for early detection of efficacy or futility. Rajasingham estimated their sample size using a presumed relative treatment effect based on recommendations by the FDA on the minimum efficacy of a COVID-19 vaccine (planned for $50 \%$ relative effect, assuming $10 \%$ event rate in control the arm). However the timing of this study meant that enrolment was problematic and due to the early termination for this reason the study was underpowered to eventually detect a difference.

\section{Treatment effect}

The treatment effect from the four trials in terms of the primary outcome (and PCR confirmed COVID) are shown in Table 2. The treatment effect is summarised as both absolute risk difference and relative risk (risk ratio). A number of summary statistics could be used to combine this information including metrics such as the number needed to treat

Table 2: Primary outcome results for hydroxychloroquine prophylaxis randomized controlled trials.

\begin{tabular}{|c|c|c|c|c|c|c|c|c|}
\hline \multirow[t]{2}{*}{ Study } & \multirow[t]{2}{*}{$\mathbf{N}$} & \multirow[t]{2}{*}{ Outcome } & \multicolumn{2}{|c|}{ Control } & \multicolumn{2}{|l|}{ HCQ } & \multirow{2}{*}{$\begin{array}{l}\text { Relative risk }{ }^{1} \\
(95 \% \mathrm{CI})\end{array}$} & \multirow{2}{*}{$\begin{array}{l}\text { Absolute risk } \\
\text { difference }^{1} \\
(95 \% \mathrm{Cl})\end{array}$} \\
\hline & & & n & event & $\mathbf{n}$ & event & & \\
\hline \multicolumn{9}{|l|}{ Pre exposure prophylaxis } \\
\hline Abella, et al. [19] & 125 & PCR confirmed COVID-19 & 61 & 4 & 64 & 4 & $0.95(0.25,3.64)$ & $\begin{array}{l}-0.3 \% \\
(-8.9 \%, 8.3 \%)\end{array}$ \\
\hline Rajasingham, et al. [18] & 1483 & $\begin{array}{l}\text { PCR confirmed or probable } \\
\text { COVID-19 }\end{array}$ & 494 & 39 & 989 & 58 & $0.74(0.50,1.10)$ & $\begin{array}{l}-2.0 \% \\
(-4.8 \%, 0.8 \%)\end{array}$ \\
\hline \multicolumn{9}{|c|}{ Post exposure prophylaxis } \\
\hline Mitja, et al. [17] & 2134 & $\begin{array}{l}\text { PCR confirmed } \\
\text { symptomatic COVID-19 }\end{array}$ & 1198 & 64 & 1116 & 74 & $\begin{array}{l}0.89 \\
(0.54,1.46)\end{array}$ & $\begin{array}{l}-0.6 \% \\
(-2.5 \%, 2.5 \%)\end{array}$ \\
\hline Boulware, et al. [16] & 821 & $\begin{array}{l}\text { PCR confirmed or probable } \\
\text { COVID-19 }\end{array}$ & 407 & 58 & 414 & 49 & $\begin{array}{l}0.83 \\
(0.58,1.18)\end{array}$ & $\begin{array}{l}-2.4 \% \\
(-7.0 \%, 2.2 \%)\end{array}$ \\
\hline
\end{tabular}

HCQ: Hydroxychloroquine; PCR: Polymerase Chain Reaction; Abella, et al. [19]: Treatment effects are presented for hydroxychloroquine compared to control arm; Rajasingham, et al. [18]: Rajasingham results are presented for pooled hydroxychloroquine arms; Mitja, et al. [17]: Risk differences for Mitja are calculated relative to event rate in control arm using reported relative risks to account for cluster study design. 
Citation: Usher C, Larsen LT, Fogarty E, et al. (2021) Absence of Evidence or Evidence of Absence - A Review of the Evidence for Hydroxychloroquine as a Potential Candidate for Prophylaxis against COVID-19. Ann Public Health Reports 5(1):160-165

Table 3: Adverse events in safety population for hydroxychloroquine prophylaxis randomized control trials.

\begin{tabular}{|l|l|l|l|l|l|l|l|l|}
\hline & N & \multicolumn{3}{|l|}{ Control } & \multicolumn{3}{l|}{ Hydroxychloroquine } & \multicolumn{2}{l|}{ p-value } \\
\cline { 3 - 9 } & & n & Any adverse event & n & Any adverse event \\
\hline Abella, et al. [19] & 130 & 65 & 17 & $26 \%$ & 65 & 29 & $45 \%$ & 0.03 \\
\hline Rajasingham, et al. [18] & 1405 & 469 & 100 & $21 \%$ & 936 & 316 & $34 \%$ & $<0.001$ \\
\hline Mitja, et al. [17] & 2497 & 1300 & 77 & $6 \%$ & 1197 & 671 & $56 \%$ & $<0.001$ \\
\hline Boulware, et al. [16] & 700 & 351 & 59 & $17 \%$ & 349 & 140 & $40 \%$ & $<0.001$ \\
\hline
\end{tabular}

Rajasingham, et al. [18]: Rajasingham results are presented for pooled hydroxychloroquine arms.

(NNT), hazard ratio (HR) or odds ratio (OR) however there are challenges associated with each of these given the available data and the trial designs. Results for adverse events are presented in Table 3. In the pre-exposure studies gastrointestinal adverse events were the most commonly reported. In the Rajasingham study this was more notable in the hydroxychloroquine twice weekly group. Abella, et al. reports that diarrhoea was the main adverse events reported; no cardiac events were observed. A similar trend was noted in the post-exposure prophylaxis studies where diarrhoea, nausea and abdominal discomfort were the most commonly reported; cardiac adverse events were not observed.

\section{Discussion}

This review identified four RCT studies which examined the potential role of $\mathrm{HCQ}$ as a prophylactic agent against COVID-19. None of the four studies demonstrated a statistical difference in infection rates between participants who took the $\mathrm{HCQ}$ and those taking placebo. While all studies showed a lack of effect of $H C Q$, infection levels were low within the trial cohorts which could be due to the effectiveness of other protective measures utilised in the healthcare system, such as $\mathrm{PPE}$, proper hand hygiene and respiratory etiquette and social distancing. It should also be noted that at the same time, the majority of these trials were underpowered to show an effect, which highlights the need for a large (possibly global collaborative effort) trial to definitively address this question. Further the timing of the trials was at a point in the pandemic when infection rates were beginning to drop due to strict preventative measures.

A meta-analysis of multiple trials can be a useful way to borrow power when the effect in one study alone is associated with uncertainty. However we did not believe combining the information in this way was appropriate in this case given the significant described heterogeneity between the studies. In order for the results to be easily interpretable by those wishing to make decisions from a public health perspective, we have provided a common estimate of treatment effect in the 'absolute risk difference'.

While the studies reported thus far have shown no statistically significant effect for HCQ as a prophylactic measure, this should not diminish the value of the results presented by the authoring teams of the RCTs to the global community. The results are consistent in demonstrating a small, if any, absolute risk difference in the populations investigated. Thus, a key question that these trials have inadvertedly highlighted is; would a larger scale trial (running for a sufficient length of time) definitively answer the question on the efficacy of hydroxychloroquine as a prophylactic agent? While small trials can be set up quickly, they have an inherent disadvantage of only being able to detect large improvements in outcomes. With few patients, it is difficult to detect even moderate differences in outcome between treated and untreated patient groups and these differences cannot easily be distinguished from chance. Large trials follow more patients and so can detect smaller differences in outcomes between treatment and control groups.

One such trial that is proceeding is COPCOV [20]: A double-blind, randomised, placebo controlled trial which aims to recruit 40,000 healthcare workers from Europe, Africa, Asia and South America. Participants are randomised to receive either chloroquine (Asia) / hydroxychloroquine (Europe) or placebo (1:1 randomisation). A loading dose of $10 \mathrm{mg}$ base/ $\mathrm{kg}$, followed by $155 \mathrm{mg}$ daily ( $250 \mathrm{mg}$ chloroquine phosphate salt or $\mathbf{2 0 0} \mathrm{mg}$ hydroxychloroquine sulphate) is taken for 3 months. Evidence is available that the dosing strategy employed by COPCOV trialists is safe [21]. However, there are already challenges, one of which is participant recruitment and infection rates among HCWs. If over the course of the trial, not enough participants have become infected by COVID-19 in either arm of the trial, it will be very hard to perform a rigorous statistical analysis of whether the approach works. While it is likely that this trial won't provide a sufficiently robust evidence base to guide practice over the coming months, it may help in addressing some of the shortcomings of the trials published so far. The critique we have provided of the current evidence gaps points towards a situation whereby a larger scale randomized control trial enrolling a high risk population in a PEP setting, which ensures a more targeted exposure in terms of both the intervention and the population enrolled, would go some way towards definitively answering the question.

The ongoing COVID-19 pandemic has, without doubt, had a profound effect on the lives of people globally. An effective vaccination programme currently represents the 'next step' to be deployed along with existing public health measures to limit the impact of the disease. While an objective of any vaccination programme will undoubtedly be to reduce the morbidity and mortality associated with the disease, it is accepted that controlling this pandemic will require many tools in the long term. It is therefore important that the likes of COPCOV and other clinical trials investigating prophylactic regimens are able to continue and have the ability to adapt to the ever changing scientific landscape so that the evidence being generated is supporting clinical practice in real time. 
Citation: Usher C, Larsen LT, Fogarty E, et al. (2021) Absence of Evidence or Evidence of Absence - A Review of the Evidence for Hydroxychloroquine as a Potential Candidate for Prophylaxis against COVID-19. Ann Public Health Reports 5(1):160-165

There are some limitations with this review which should be addressed, primarily generating a common estimate of treatment effect when there is such heterogeneity exhibited between trials. Apart from the heterogeneity exhibited in the studies included, a significant bias in the review of treatments for COVID-19 has been the steep learning curve from January 2020 to present, which has affected personal and clinical practices during this time, making comparisons between studies and inferences regarding treatments difficult.

Despite advances in supportive care and treatment, mortality remains high, and prevention of infection continues to be crucial. Several other therapeutic options for prophylactic therapy have commenced in clinical trials, and one which is gaining traction is ivermectin [22,23]. However, a word of caution - while there may be a signal to evaluate further, many of the trials in these studies [22] are methodogically flawed without enough information on baseline demographics, they contain multiple primary outcomes, lack of consistency in definitions used, as well as a lack of background information on COVID-19 rates in the countries studied [23] - much the same as was highlighted in this paper regarding the hydroxychloroquine trials. While the global community yearns for and deserves to get an effective prophylactic treatment option for COVID-19, let's learn from the lessons served up with hydroxychloroquine.

\section{Conclusion}

There is currently no robust evidence to support the use of $\mathrm{HCQ}$ prophylactic therapy in healthcare workers or those in contact with cases of COVID-19 outside of clinical trials. Evidence from four RCTs of hydroxychloroquine has so far not demonstrated an absolute effect in preventing COVID-19 infection; however the trials did have some shortcomings. Even though a beneficial effect has not been shown, the challenges and shortcomings faced in these trials should aid in the design and or adaptation of future trials. This review finds that there remains an absence of robust evidence to address whether PREP or PEP regimens with hydroxychloroquine will be a useful tool in the prevention of infection with SARS-CoV-2. Our analysis shows a smaller effect if any of hydroxychloroquine than previously anticipated. Therefore further evidence from larger controlled adequately powered clinical trials will hopefully address the question on whether there will be evidence of absence.

\section{References}

1. Amnesty International (2020) Exposed, silenced and attacked: Failures to protect health and essential workers during the COVID-19 pandemic. Amnesty International and Peter Benenson House, London, UK.

2. Maxwell DN, Perl TM, Cutrell JB (2020) "The art of war" in the era of coronavirus disease 2019 (COVID-19). Clin Infect Dis 71: 2215-2217.

3. Welliver R, Monto AS, Carewicz O, et al. (2001) Effectiveness of oseltamivir in preventing influenza in household contacts: A randomized controlled trial. JAMA 285: 748-754.

4. Cardo DM, Culver DH, Ciesielski CA, et al. (1997) A case-control study of HIV seroconversion in health care workers after percutaneous exposure. Centers for disease control and prevention needlestick surveillance group. N Engl J Med 337: 1485-1490.
5. Grant RM, Lama JR, Anderson PL, et al. (2010) Preexposure chemoprophylaxis for HIV prevention in men who have sex with men. New England Journal of Medicine 363: 2587-2599.

6. McCormack S, Dunn DT, Desai M, et al. (2016) Pre-exposure prophylaxis to prevent the acquisition of HIV-1 infection (PROUD): Effectiveness results from the pilot phase of a pragmatic open-label randomised trial. Lancet 387: 53-60.

7. Molina JM, Capitant C, Spire B, et al. (2015) On-demand pre-exposure prophylaxis in men at high risk for HIV-1 infection. New England Journal of Medicine 373: 2237-2246.

8. (2015) WHO expands recommendation on oral pre-exposure prophylaxis of HIV infection (PrEP) Copenhagen. World Health Organization.

9. Zhou D, Dai SM, Tong Q (2020) COVID-19: A recommendation to examine the effect of hydroxychloroquine in preventing infection and progression. J Antimicrob Chemother 75: 1667-1670.

10. Liu J, Cao R, Xu M, et al. (2020) Hydroxychloroquine, a less toxic derivative of chloroquine, is effective in inhibiting SARS-CoV-2 infection in vitro. Cell Discovery 6: 16.

11. Yao X, Ye F, Zhang M, et al. (2020) In vitro antiviral activity and projection of optimized dosing design of hydroxychloroquine for the treatment of severe acute respiratory syndrome coronavirus 2 (SARS-CoV-2). Clin Infect Dis 71: 732-739.

12. Patrı A, Fabbrocini $G$ (2020) Hydroxychloroquine and ivermectin: A synergistic combination for COVID-19 chemoprophylaxis and treatment? J Am Acad Dermatol 82: e221.

13. Pan $\mathrm{H}$, Peto $\mathrm{R}$, Karim QA, et al. (2020) Repurposed antiviral drugs for COVID-19- interim WHO SOLIDARITY trial results. Med Rxiv NEJMoa2023184.

14. The Recovery Collaborative Group (2020) Effect of hydroxychloroquine in hospitalized patients with Covid-19. N Engl J Med 383: 2030-2040.

15. COVID-19 Evidence Review Group, National Centre for Pharmacoeconomics, Ireland (2020) Clinical evidence on the use of pharmacological prophylactic therapy in healthcare workers or contacts of cases of COVID-19. National Centre for Pharmacoeconomics 1-35.

16. Boulware DR, Pullen MF, Bangdiwala AS, et al. (2020) A randomized trial of hydroxychloroquine as postexposure prophylaxis for COVID-19. New England Journal of Medicine 383: 517-525.

17. Mitjà $O$, Corbacho-Monné $M$, Ubals $M$, et al. (2020) A cluster-randomized trial of hydroxychloroquine for prevention of Covid-19. New England Journal of Medicine NEJMoa2021801.

18. Rajasingham R, Bangdiwala AS, Nicol MR, et al. (2020) Hydroxychloroquine as pre-exposure prophylaxis for COVID-19 in healthcare workers: A randomized trial. Clinical Infectious Diseases ciaa1571.

19. Abella BS, Jolkovsky EL, Biney BT, et al. (2020) Efficacy and safety of hydroxychloroquine vs placebo for pre-exposure SARS-CoV-2 prophylaxis among health care workers: A randomized clinical trial. JAMA e206319.

20. University of Oxford (2020) Chloroquine/ hydroxychloroquine prevention of coronavirus disease (COVID-19) in the healthcare setting (COPCOV). Clinical Trials.gov Identifier: NCT04303507.

21. White NJ, Watson JA, Hoglund RM, et al. (2020) COVID-19 prevention and treatment: A critical analysis of chloroquine and hydroxychloroquine clinical pharmacology. PLoS Med 17: e1003251.

22. Hellwig MD, Maia A (2020) A COVID-19 prophylaxis? lower incidence associated with prophylactic administration of Ivermectin. International Journal of Antimicrobial Agents 57: 106248.

23. Kory Pierre, Meduri Jose Iglesias G, Joseph Varon DO, et al. (2020) Review of the emerging evidence demonstrating the efficacy of ivermectin in the prophylaxis and treatment of COVID-19. 